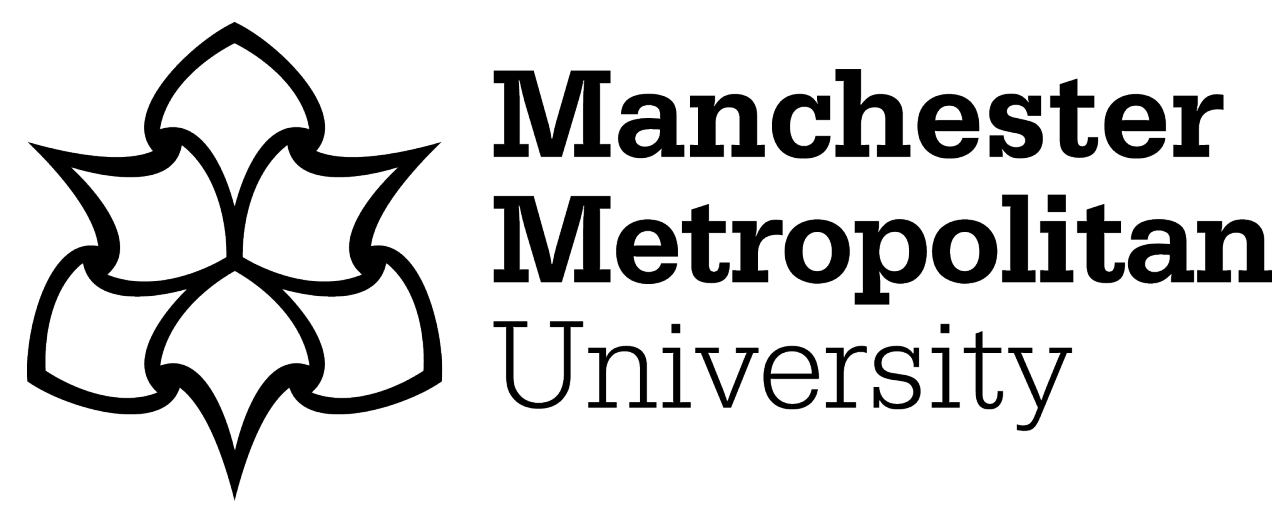

Hatfield, Jack H, Barlow, Jos, Joly, Carlos A, Lees, Alexander C ORCID logoORCID: https://orcid.org/0000-0001-7603-9081, de Freitas Parruco, Celso H, Tobias, Joseph A, Orme, C David L and Banks-Leite, Cristina (2020) Mediation of area and edge effects by adjacent land use. Conservation Biology, 34 (2). pp. 395-404. ISSN 0888-8892

Downloaded from: https://e-space.mmu.ac.uk/623572/

Version: Accepted Version

Publisher: Wiley

DOI: https://doi.org/10.1111/cobi.13390

Please cite the published version 


\section{Mediation of area and edge effects by adjacent land use}

2

3

4

5

Jack H. Hatfield ${ }^{1 *}$, Jos Barlow², Carlos A. Joly ${ }^{3}$, Alexander C. Lees ${ }^{4,5}$, Celso H. de Freitas Parruco $^{6}$, Joseph A. Tobias ${ }^{1}$, C. David L. Orme ${ }^{1}$, Cristina Banks-Leite ${ }^{1,7}$

${ }^{1}$ Grand Challenges in Ecosystems and the Environment, Department of Life Sciences, Imperial College London, Silwood Park Campus, Ascot SL5 7PY, UK.

${ }^{2}$ Lancaster Environment Centre, Lancaster University, LA1 4YQ

${ }^{3}$ Departamento de Biologia Vegetal, Instituto de Biologia, Universidade Estadual de Campinas, Rua Monteiro Lobato 255, 13083-862, Campinas, São Paulo, Brazil

${ }^{4}$ School of Science and the Environment, Manchester Metropolitan University, Manchester, M1 5GD, UK

${ }^{5}$ Cornell Lab of Ornithology, Cornell University, Ithaca, NY 14850, USA

${ }^{6}$ ES - Ecological Solutions Consultoria Ambiental Ltda.

${ }^{7}$ Department of Ecology, Biosciences Institute, University of São Paulo, 05508-090 São Paulo SP, Brazil.

* Corresponding author - jack.hatfield12@imperial.ac.uk

Keywords: plantations, pasture, habitat fragmentation, forest cover, patch size

Running head: Matrix mediates fragmentation effects

\section{Abstract}


Habitat loss, fragmentation and degradation have pervasive detrimental effects on tropical forest biodiversity, but the role of the surrounding land use (i.e. matrix) in determining the severity of these impacts remains poorly understood. We surveyed bird species across an interior-edge-matrix gradient to assess the effects of matrix type on biodiversity at 49 different sites with varying levels of landscape fragmentation in the Brazilian Atlantic Forest - a highly threatened biodiversity hotspot. Our findings revealed that both area and edge effects are more pronounced in forest patches bordering pasture matrix, while patches bordering Eucalyptus plantation maintained compositionally similar bird communities between the edge and the interior, in addition to exhibiting reduced effects of patch size. These results suggest that the type of matrix in which forest fragments are situated can explain a substantial amount of the widely-reported variability in biodiversity responses to forest loss and fragmentation.

\section{Introduction}

The type of matrix surrounding native forest patches in human-modified landscapes can modulate the responses of species and ecological communities to habitat loss and degradation (Brockerhoff et al., 2008; Prevedello \& Vieira 2010). However, the mechanisms through which the matrix influences the effects of habitat change on biodiversity are still unclear. For instance, do inhospitable matrix types accelerate the local extinction of sensitive species in fragmented landscapes or promote the invasion of disturbance-tolerant species? Are patch area effects less pronounced (Prugh et al. 2008) in a permeable matrix because of rescue effects or weaker edge effects? Answering these questions is crucial if we are to manage matrix land uses to reduce biodiversity loss (Driscoll et al. 2013).

With the growing recognition that some matrix types are more permeable and hospitable to some species than others (Brockerhoff et al. 2008; Felton et al. 2010), recent research has increasingly focused on the interplay between matrix type and landscape composition (Driscoll et al. 2013). However, the extent to which matrix type can modulate biodiversity responses to area, edge and isolation remains controversial (Prugh et al. 2008; 
Prevedello \& Vieira 2010; Watling et al. 2011). Prugh et al. (2008) found isolation and area to

be poor predictors of species occupancy when matrix type was highly permeable (e.g. seminatural habitats), while area and isolation were strong predictors of biodiversity in more hostile types of matrix. This is logical as any increase in structural similarity between the matrix and habitat patches can increase population connectivity among patches (Renjifo 2001; Prevedello \& Vieira 2010), reducing local extinction by means of rescue effects. On the other hand, Prevedello and Vieira (2010) argued that these matrix effects are smaller and more species-specific than those of area and isolation.

The capacity of the matrix to buffer edge effects is expected to increase if matrix habitats approximate to the physiognomy of native habitats, reducing the impact of biotic and abiotic gradients at edges (Banks-Leite \& Ewers 2009). For example, Amazonian tree mortality appears to be higher at edges bordering cattle pastures than those bordering secondary forests (Mesquita et al. 1999). Shade coffee plantations have also been found to dampen edge effects in tropical montane forest when compared to corn plantations (Santos-Barrera \& Urbina-Cardona 2011). Other effects such as spill-over of matrix species into forest patches may create an influx of disturbance-tolerant species, with concomitant high species turnover (Banks-Leite et al. 2012, 2014) and changes to ecosystem function (De Coster et al. 2015). Changes in species composition can be problematic when they involve large-scale biotic homogenisation, involving the proliferation of generalist species and the decline or local extinction of many specialists (Solar et al. 2015). Given the likely complexity of the underlying mechanisms governing these changes in community assembly, a rigorous landscape-based approach (Fahrig 2003) is required to determine the propensity of the matrix to influence the effects of habitat loss and landscape configuration (i.e. isolation, patch area and edge effects).

To examine the ability of the matrix to mitigate the detrimental effects of landscape configuration on biodiversity, we considered bird communities in the highly fragmented and biodiverse Brazilian Atlantic Forest (Myers et al. 2000; Ribeiro et al. 2009). To obtain a full picture of how bird communities change, we collected data with four temporal replicates spanning seasonal variation, stratifying sampling across fragment interiors, fragment edges 
and the surrounding matrix. Within this framework we examined both a habitat fragmentation gradient and different matrix types. To better understand how community composition changes, we analysed species richness, community integrity (compositional similarity to continuous forest) and richness of both forest-dependent and disturbance-tolerant species. Disturbance-tolerant species richness was expected to be higher in fragments surrounded by the open pasture matrix with forest species being more commonly associated with fragments bordered by plantation forest. We also expected that a Eucalyptus plantation matrix, which bears higher structural similarity to Atlantic Forest, would show reduced edge and area effects when compared to an open pasture matrix.

\section{Methods}

\section{Study Design}

The study area was located in the Vale do Paraíba and Serra do Mar regions in the state of São Paulo, Brazil. The area is composed of sub-montane forest of varying age surrounded by a range of matrix types. The mean native forest cover at the 10,000-ha scale across all sites was $30 \%$ with mean total forest cover being $40 \%$ and altitude varying between 600 and 1130 m (Appendix S1). Continuous forest sites were located within the largest remaining wellconnected forest patch network comprising over one million ha (Ribeiro et al. 2009). We surveyed a total of 49 sites, including 15 near continuous reference sites and 34 fragmented forest sites. At each site, we sampled three transects with three point count stations each. Points within transects were approximately $75 \mathrm{~m}$ apart (where terrain and landscape configuration allowed) and the three transects were also spaced by $75 \mathrm{~m}$ (Fig. 1). This design was chosen to ensure that even small forest fragments could be surveyed with equal effort. In fragmented forest sites, a single transect was conducted in each of three positions relative to the focal forest patch; patch interior, patch edge and in the matrix bordering the focal patch (Fig. 1). 

median patch size was 28 ha. There were six different transect types surveyed across the fragmented forest sites, representing the six unique combinations of position (interior, edge or matrix) and matrix land use (Eucalyptus plantation or cattle pasture). Due to availability and accessibility, as well as the mosaic nature of the landscape, patches were not surrounded by a uniform matrix; however, all transects were conducted in areas of the patch that bordered the chosen matrix type. Surveyed fragments were selected to sample the full range of fragment area and connectivity found in the study region and were part of the *name removed for review* project (Appendix S1). The 15 reference sites were chosen to encompass one land use each, and we thus sampled five large areas of forest (CF), five large areas of cattle pasture $(\mathrm{CP})$, and five large Eucalyptus plantations (CE). Continuous sites were designed with the same grid configuration as explained above, but with all transects conducted in the same land use type.

\section{Avifaunal surveys}

Bird surveys were conducted between December 2015 and February 2017 using point counts. Each count was 15 minutes in duration, during which we recorded all birds identified within a $25 \mathrm{~m}$ radius of the point, with four temporal replicates (equally split between wet and dry seasons) per point. The spatial and temporal replicate points for each of the 147 transects were then aggregated, providing a sampling effort of 12 point counts per transect. Species richness was calculated as the total number of species recorded at each transect. We also calculated a frequency of occurrence (i.e. an encounter rate) for each species in each transect. This was done by summing the number of times the species was detected at a site, a measure that ranged between 0 and 12, thus providing a proxy for abundance (Solar et al. 2015). This minimised the influence of single detections, which was especially useful for the matrix surveys where some species may be transients infrequently recorded passing between forest patches. From the frequency of occurrence, we calculated community composition based on a BrayCurtis dissimilarity matrix using the $R$ package vegan (Oksanen et al. 2016). Values were then 
assigned based on the scores from the first axis of a Principal Coordinate Analysis conducted on the dissimilarity matrix. For fragmented sites we used community integrity rather than community composition to allow comparison to continuous forest. Community integrity used the raw distances extracted from the Bray-Curtis dissimilarity matrix calculating the mean distance between each transect and the continuous forest transects. This Bray-Curtis distance was then subtracted from 1 to provide a scale where 1 indicates a transect that highly resembles control forest and 0 indicates transects extremely dissimilar from continuous forest hence community integrity can be seen as a measure of similarity to the reference continuous forest (for a similar approach see De Coster et al. 2015).

\section{Landscape metrics}

Forest cover (\%) was measured for each site using radii of $600 \mathrm{~m}, 800 \mathrm{~m}, 1,500 \mathrm{~m}$, and 3,000 $\mathrm{m}$ from the centre of the site and for the 10,000-ha landscape ( 5 by $5 \mathrm{~km}$, hereafter: landscape forest cover). A single forest cover scale was chosen per model based on model fit because multiple scales could not be modelled together due to high levels of collinearity (Appendix S2). We also measured size and proximity index (800 m search distance) for focal fragments with details see Appendix S1.

\section{Data analysis}

All analysis was conducted in R v.3.3.2 (R Core Team 2016). We examined the effect of transect type (the combination of position and matrix type) using mixed effect modelling in Ime4 (Schielzeth \& Nakagawa 2013) with site as a random factor to account for spatial dependency between transects in the same landscape. For species richness, a generalised linear mixed model (Poisson error structure checked for over-dispersion (Appendix S1)) was 
used and community composition metrics used linear mixed models. The influence of transect type on the avifaunal community was only investigated for the 34 fragmented sites; with the position and matrix land use combination (e.g. Interior-Pasture) as a single fixed effect, conducting post-hoc contrasts to assess significance. Although we do not include p-values from our main results, we provide them with the mixed effects models for factor level contrasts to aid in interpretation. The continuous sites were not included in the models because there was only one land use type surveyed at each of these sites, however, we analysed them separately to provide a baseline for comparison. The data was then partitioned into interior, edge and matrix to investigate the effects of landscape metrics using linear and generalised linear models. Landscape metric models were selected based on AICc (due to small sample size) or F tests in the case of overdispersion (Appendix S1). Due to small sample sizes, we were unable to fit all the interactions. We did however fit the interactions between matrix type and the other metrics as investigating the effect of matrix type is a major aim of this study. Plots from models containing multiple explanatory variables used partial residuals (Appendix S1).

We conducted analyses on the whole bird community as well as two subsets - termed forest species and disturbance-tolerant species owing to the high species turnover observed in Atlantic Forest bird communities (Banks-Leite et al. 2012, 2014). By dividing the community into two groups we were able to reveal trends that are concealed by turnover when examining the community as a whole; for example, whether compositional changes are governed by loss of forest species or gain of disturbance-tolerant species. These groups represented those species associated with the fragmented areas and those associated with the intact areas. Thus, this allowed us to individually consider those species responding negatively to disturbance and those that respond in a positive manner, but our categorisation is not intended as a definitive classification. These distinctions were created using a species ranking system based on weighted averages ordination (Banks-Leite et al. 2014). Species presence/absence was first weighted by site scores taken from the first axis of a PCoA based on Bray-Curtis 
dissimilarity. The mean is then calculated from all non-zero weights. The division was made relative to the mean of the site scores (the value for a species that occurs at all sample locations).

Our method for partitioning the community into groups is a post-hoc approach based on observed species turnover across sites. We favoured this approach because previous classifications of species sensitivity or habitat use, such as Parker III et al. (1996), are not transparent regarding where data were obtained, the level of uncertainty associated with each classification, and do not separate between different stressors (e.g. a species may be sensitive to hunting but insensitive to the land use changes we investigated here)(Alexandrino et al. 2016). Our approach thus allowed us to identify the "winners" (i.e. disturbance-tolerant) and "losers" (i.e. forest-associated species) in our dataset. We then used information on forest habitat restriction to better understand how our approach of community partitioning was related to the previous classification of Parker III et al. (1996) - with taxonomic disagreement resolved following the checklist produced by BirdLife International (2017). Estrilda astrild was excluded from this comparison due to a lack of habitat usage information.

Site-scale analyses were conducted by aggregating the three transects at each site. This produced a frequency of occurrence for each species potentially ranging between 0 and 36 from which community integrity was calculated. Species richness and community integrity were modelled against percentage forest cover for the 10,000-ha landscape and matrix type surveyed using generalised linear and linear models, respectively.

\section{$\underline{\text { Results }}$}

Overall we detected 267 species across the 49 landscapes. The first PCoA axis explained $27.6 \%$ of the total variance. Using the weighted averages approach, the community was split into 177 forest species and 90 disturbance adapted species. When compared to habitat usage information in Parker III et al. (1996), 72\% of species that we assigned to the forest species group were found to be restricted to forest habitats based on the published information, 
compared with $2 \%$ of the species in disturbance-tolerant group. Although we do not examine

214 this further, these comparisons demonstrate that our community split tallies well with published classifications.

\section{Continuous sites}

217 Analyses of the whole community revealed that both continuous plantation $(z=-5.56, p<0.01)$ and continuous pasture $(z=-6.82, p<0.01)$ did not differ significantly from one another but both showed lower species richness than continuous forest transects (Fig. 2a). However, the community composition of three transect types were all significantly different from each other (Fig. 2b; CE - CF: $z=-14.24, p<0.01 ; C P-C F: z=-26.07, p<0.01 ; C P-C E: z=-11.83, p$ $<0.01)$. Changes in community composition were driven by a decrease in forest species richness in both types of matrix, together with an increase in disturbance-tolerant species (Fig. 2c, d). All continuous blocks were significantly different from each other in forest species (CE $-C F: z=-7.79, p<0.01 ; C P-C F: z=-12.38, p<0.01 ; C P-C E: z=-6.63, p<0.01)$ and disturbance-tolerant species richness $(\mathrm{CE}-\mathrm{CF}: \mathrm{z}=4.94, p<0.01 ; \mathrm{CP}-\mathrm{CF}: \mathrm{z}=9.21, \mathrm{p}<$ $0.01 ; C P-C E: z=6.90, p<0.01)$.

\section{Fragmented forest sites}

Transect type (i.e. position and matrix combination) influenced total species richness in the fragments $(F=32.83)$. Species richness in the matrix was significantly lower than both edge and interior (Figure $2 \mathrm{e}$ ), and pasture matrix transects had on average $39 \%$ more species than Eucalyptus $(z=6.10, p<0.01)$. The results for community integrity however showed a different trend. Although transect type continued to have a significant influence ( $F=194.69)$, edge effects were only observed in patches bordering pasture, while forest patches bordering Eucalyptus presented similar levels of integrity at edges and interiors (Fig. 2f), mirroring results for continuous sites, where Eucalyptus transects had higher integrity than pasture transects (Fig. 2f). 

increase in disturbance-tolerant species rather than a reduction in forest species. The richness of forest species did not differ between edge and interior, regardless the bordering matrix (Fig. $2 g ; z=-5.31, p<0.01)$, but the richness of disturbance-tolerant species in patches bordering pasture was lower in forest interiors when compared to edges $(z=-3.68, p<0.01)$. Furthermore, the species richness of disturbance-tolerant species in the interior of patches bordering pasture was, on average, 1.9 times higher than fragment interiors bordering Eucalyptus ( $p=0.02)$, and similar to the number of species found in Eucalyptus matrix.

Landscape configuration

$\underline{\text { Interior and edge }}$

Interior and edge transects showed a similar mediation of matrix type on community integrity responses to landscape configuration and habitat amount (Interior: adj- $R^{2}=0.57$; Edge: adj$\left.R^{2}=0.55\right)$. In both cases, integrity was only positively affected by patch size in fragments bordering pasture (Fig. 3a and 4a; Interior: $t=2.12, p=0.04$; Edge: $t=2.87, p<0.01$ ). Landscape forest cover (10,000-ha) on the other hand positively influenced integrity both in pasture and Eucalyptus bordering fragments (Interior: $\mathrm{t}=5.11, \mathrm{p}<0.01$; Edge: $\mathrm{t}=3.98, \mathrm{p}<$ 0.01), and while the slope of this relationship was not affected by matrix type, the intercept was always higher in Eucalyptus bordering patches (Fig. 3b and 4b). None of the landscape metrics (e.g. forest cover, patch size, proximity index) significantly correlated with species richness for interior transects whereas for edge transects total species richness was found to decrease with forest cover at the $3 \mathrm{~km}$ scale $(z=-2.04, p=0.04)$.

Forest species richness was not significantly affected by any landscape metric, but the richness of disturbance-tolerant species found at interior (Fig. 3c; $t=-2.14, p=0.03$ ) and edge (Fig. 4c; $t=-2.29, p=0.03$ ) transects was negatively correlated with patch size only in pasture 
reduced with forest cover; the intercept was different between the matrix types, but the slope was the same $(z=-2.53, p=0.01)$.

$\underline{\text { Matrix }}$

Community integrity was lower for pasture matrices than plantation $(t=-5.95, p<0.01)$, and integrity was positively correlated with patch area (Fig. $4 e, t=2.06, p=0.05, \operatorname{adj} R^{2}=0.53$ ). Species richness was influenced by matrix type with pasture matrices having higher richness $(t=4.10, p<0.01)$.

Forest species richness was positively correlated with forest patch area (Fig. 4f, $t=$ 2.57, $\mathrm{p}=0.02)$ and pasture matrices had lower forest species richness than plantation $(\mathrm{t}=$ $3.55, p<0.01)$. Disturbance-tolerant species richness was only significantly affected by matrix type, with pasture matrices having higher richness $(t=9.25, p<0.01)$.

\section{Site scale}

At the site scale (Interior, edge and matrix transects combined; Fig. 5) community integrity was found to increase with forest cover $(t=3.06, p<0.01)$ with fragments bordering pasture having lower integrity than those bordering plantations $(t=-3.10, p<0.01)$, yielding an adjusted- $R^{2}$ of 0.42 . Species richness was only affected by matrix type with pasture bordering fragments having more species $(z=5.90, p<0.01)$.

\section{Discussion}

We found that Eucalyptus plantation matrices were more beneficial for bird communities in the Atlantic Forest when compared to pasture matrices. Although pastures had higher species richness than Eucalyptus plantations, forest fragments bordering Eucalyptus have higher community similarity to continuous forest and weaker edge effects (Fig. 2, 3 and 4). We also show that the strengthening of edge and area effects in patches bordering pastures was mostly due to the increase in disturbance-specialists, rather than the loss of forest species. 
Nonetheless, our findings suggest that spill-over of species can occur in both directions in fragmented tropical forests, from fragments to matrix and vice versa.

In our study landscape, the Eucalyptus plantation matrix supported fewer bird species than pasture yet retained more forest species (Fig. 2). This aligns with previous studies showing that non-native plantations provide habitat for a small subset of tropical forest species (Barlow et al. 2007; Lees et al. 2015; Millan et al. 2015), without acting as a species source (Hawes et al., 2008). Pastures, on the other hand, not only provide a habitat for different species (Moura et al. 2013; Lees et al. 2015), but also allow them to spill-over into native forest, as shown by the increase in the richness of disturbance-tolerant species in fragments (Fig. 2h and 3c). We also found evidence of reverse spill-over effects from the forest into the surrounding pasture (Tscharntke et al. 2012) in contrast to Boesing et al. (2018a) who found minimal spill-over of birds into cattle pasture in the Atlantic Forest. Our results suggest that community integrity in matrix transects increases with forest patch area (Fig. 4e), indicating that large native forest patches help maintain community integrity in the surrounding matrix.

These results reinforce previous findings highlighting the value of extensive forest patches in providing source populations of forest-dependent bird species (Mayhew et al. 2019), thereby enriching the surrounding matrix via a spill-over of ecosystem services, such as pollination, pest control and seed dispersal. Spill-over of services has been widely documented for a range of taxa (Tscharntke et al. 2012) including insect and bird pollinators (Renjifo 2001; Ricketts et al. 2008) and bird spill-over has been shown to be particularly important in coffee plantations (Boesing et al. 2018a), where birds control populations of pests (Johnson et al. 2010). Hence, species spill-over from large forest patches into the matrix may benefit crop productivity while also increasing seed dispersal of native trees which is key to natural reforestation and forest recovery (Bregman et al. 2016).

Edge effects are prominent in the Atlantic Forest bird community (Banks-Leite et al. 2010; Ewers \& Banks-Leite 2013; Pfeifer et al. 2017) where they are thought to drive the widely 
observed area effects on biodiversity in this fragmented landscape (Ewers et al. 2007; Fletcher et al. 2007; Banks-Leite et al. 2010). Our results provide further corroboration of this hypothesis as we only detected significant edge effects in patches bordering pasture matrices, where patch area also had a significant influence on the interior bird community. Conversely, for fragments with a plantation matrix, we found neither significant edge effects, nor significant area effects.

The large difference in edge effects observed could be due to two main factors. First, plantations are known to harbour fewer open matrix species (Umetsu \& Pardini 2007) limiting changes in community composition due to turnover. Second, plantations may contribute to the retention of forest species. Our results indicating that plantations may mitigate edge effects mirror those of Renjifo (2001), who found that exotic tree plantations had a buffering effect on the abundance of some forest species when compared to pasture. Ruffell et al. (2017) also found that the reduction in bird species richness with habitat loss was less severe when the matrix contained exotic tree plantations, even when plantations occupied as little as $10 \%$ of the matrix. In addition, Boesing et al. (2018b) have shown that the extinction thresholds for the bird community detected in fragments surrounded by coffee plantations was at $19 \%$ forest cover compared to $35 \%$ when the matrix is pasture.

Overall, this study supports the view that a shared border with Eucalyptus plantations is less detrimental to forest bird communities than a shared border with pasture. Eucalyptus plantations are likely able to buffer edge effects and reduce the infiltration of disturbancetolerant species into patch edges and interiors when compared to cattle pasture. They also provide higher community integrity for a given level of native forest cover. From the perspective of conservation, plantations therefore offer a management solution to reduce the impact of fragmentation on biodiversity without requiring large increases in the area of native forest. However, these potential benefits carry several caveats. 

compared with pastures. They are often structurally similar to native forest (Prevedello \& Vieira 2010), but variation in structural complexity of plantations is also important, as those with higher complexity (e.g. multiple vegetation strata) generally contain higher bird species richness and abundance (Nájera \& Simonetti 2010; Millan et al. 2015). The plantation sites surveyed in this study often retained understory foliage, a practice that is not universal, but which matches the management practices in other studies that concluded that plantations have some utility for biodiversity (e.g. Barlow et al. 2007). Thus, it is likely that the detrimental impacts of plantations on native biodiversity are much stronger when plantation understory is cleared. The cyclic nature of plantations is another important consideration: while plantations consisting of adult trees may buffer edge effects, it is unlikely that young sapling trees will provide the same benefit, especially given the large reduction in structural complexity after harvesting. Future research should focus on extending the temporal span of data collection so that the effects of plantations can be assessed throughout the harvesting cycle. There is also scope to investigate the impacts of management, for example if certain management techniques or harvesting rotations provide a higher conservation benefit than others (Moreira et al. 2013).

In the wider context of expanding plantations worldwide and especially in the case of Eucalyptus in Brazil, the benefits may be more varied and depend on the land use plantations are replacing (Brockerhoff et al. 2013). Comparisons of plantations and pasturelands have been found to be highly contingent on the taxonomic focus and landscape specifics (Felton et al. 2010). Conversion of agricultural land to plantations has also received ample attention due to the other environmental benefits they may bring, such as climate change mitigation through carbon storage and sequestration (Jackson \& Schlesinger 2004). However, other effects such as changes in soil organic carbon are less clear (Fialho \& Zinn 2014).

Manipulation of the matrix can moderate species responses to habitat loss and fragmentation and the ongoing conversion of pasturelands to plantation may yet yield benefits 
for bird biodiversity via improved connectivity among populations and the reduction of edge effects. As with secondary forests (Mayhew et al. 2019), the conservation value of plantations largely depends on the maintenance and extent of embedded native forest patches. Nonetheless, although intensive research has been conducted on the effects of management on biodiversity within plantations themselves (Nájera \& Simonetti 2010; Millan et al. 2015), little is known about how plantation management and harvesting practices affect adjacent native forests. We recommend that future research investigates how management practices mediate effects of plantations on biodiversity in adjacent forest fragments, as doing so may provide a key insight into practical conservation solutions for human modified tropical forest landscapes.

\section{Supporting Information}

Additional methods (Appendix S1), comparison of the different forest cover radii (Appendix S2) and information on species occurrence in the different land use types (Appendix S3) are available online. The authors are solely responsible for the content and functionality of these materials. Queries (other than absence of the material) should be directed to the corresponding author.

\section{Literature Cited}

Alexandrino ER, Buechley ER, Piratelli AJ, Ferraz KMPMB, Moral RA, Sekercioglu CH, Silva WR, Couto HTZ. 2016. Bird sensitivity to disturbance as an indicator of forest patch conditions: An issue in environmental assessments. Ecological Indicators, 66: 369-381.

Banks-Leite C, Ewers RM. 2009. Ecosystem Boundaries, in: Encyclopedia of Life Sciences (ELS). John Wiley \& Sons, Ltd.

Banks-Leite C, Ewers RM, Metzger JP. 2010. Edge effects as the principal cause of area effects on birds in fragmented secondary forest. Oikos 119: 918-926. 
Banks-Leite C, Ewers RM, Metzger JP. 2012. Unravelling the drivers of community dissimilarity and species extinction in fragmented landscapes. Ecology 93: 2560-2569.

Banks-Leite C, Pardini R, Tambosi LR, Pearse WD, Bueno AA, Bruscagin RT, Condez TH, Dixo M, Igari AT, Martensen AC, et al. 2014. Using ecological thresholds to evaluate the costs and benefits of set-asides in a biodiversity hotspot. Science (80-. ) 345: 1041-1045.

Barlow J, Gardner TA, Araujo IS, Avila-Pires TC, Bonaldo AB, Costa JE, Esposito MC, Ferreira L V, Hawes J, Hernandez MIM, et al. 2007. Quantifying the biodiversity value of tropical primary, secondary, and plantation forests. Proceedings of the National Academy of Sciences of the United States of America. 104: 18555-18560.

BirdLife International. 2017. Handbook of the Birds of the World and BirdLife International digital checklist of the birds of the world. Version 9.1. Available at: http://datazone.birdlife.org/species/taxonomy

Boesing AL, Nichols E, Metzger JP. 2018a. Land use type, forest cover and forest edges modulate avian cross-habitat spillover. Journal of Applied Ecology 55:1252-1264.

Boesing AL, Nichols E, Metzger JP. 2018b. Biodiversity extinction thresholds are modulated by matrix type. Ecography 41: 1520-1533.

Bregman TP, Lees AC, MacGregor HEA, Darski B, de Moura NG, Aleixo A, Barlow J, Tobias JA. 2016. Using avian functional traits to quantify the impact of land-cover change on ecosystem processes linked to resilience in tropical forests. Proceedings of the Royal Society B 283: 20161289.

Brockerhoff EG, Jactel H, Parrotta JA, Quine CP, Sayer J. 2008. Plantation forests and biodiversity: oxymoron or opportunity? Biodiversity and Conservation 17: 925-951. 
411 Brockerhoff, EG, Jactel H, Parrotta J A, Ferraz SFB. 2013. Role of eucalypt and other

412 planted forests in biodiversity conservation and the provision of biodiversity-related ecosystem services. Forest Ecology and Management 301: 43-50.

De Coster G, Banks-Leite C, Metzger JP. 2015. Atlantic forest bird communities provide different but not fewer functions after habitat loss. Proceedings of the Royal Society B Biological Sciences 282: 20142844.

Driscoll DA, Banks SC, Barton PS, Lindenmayer DB, Smith, AL. 2013. Conceptual domain of the matrix in fragmented landscapes. Trends in Ecology and Evolution 28: 605-613.

Ewers RM, Banks-Leite C. 2013. Fragmentation impairs the microclimate buffering effect of tropical forests. PLoS One 8: e58093.

Ewers RM, Thorpe S, Didham RK. 2007. Synergistic interactions between edge and area effects in a heavily fragmented landscape. Ecology 88: 96-106.

Fahrig L, 2003. Effects of Habitat Fragmentation on Biodiversity. Annual Review of Ecology, Evolution, and Systematics 34:487-515.

Felton A, Knight E, Wood J, Zammit C, Lindenmayer D. 2010. A meta-analysis of fauna and flora species richness and abundance in plantations and pasture lands. Biological Conservation 143: 545-554.

Fialho RC, Zinn YL. 2014. Changes in soil organic carbon under Eucalyptus plantations in Brazil: a comparative analysis. Land Degradation and Development 25: 428-437.

Fletcher RJJ, Ries L, Battin J, Chalfoun AD. 2007. The role of habitat area and edge in fragmented landscapes: definitively distinct or inevitably intertwined? Canadian Journal of Zoology 85: 1017-1030. design. Landscape and Urban Planning 29: 117-130. 
Hansen MC, Potapov PV, Moore R, Hancher M, Turubanova SA, Tyukavina A, Thau D, Stehman SV, Goetz SJ, Loveland TR, et al. 2013 High-Resolution Global Maps of 21stCentury Forest Cover Change. Science (80- ) 342: 850-853.

Hawes J, Barlow J, Gardner TA, Peres C.A. 2008. The value of forest strips for understorey birds in an Amazonian plantation landscape. Biological Conservation 141: 2262-2278.

Jackson RB, Schlesinger WH. 2004. Curbing the U.S. carbon deficit. Proceedings of the National Academy of Sciences of the United States of America 101: 15827-15829.

Johnson MD, Kellermann JL, Stercho AM. 2010. Pest reduction services by birds in shade and sun coffee in Jamaica. Animal Conservation 13: 140-147.

Lees AC, Moura NG, de Almeida AS, Vieira ICG. 2015. Poor prospects for avian biodiversity in Amazonian oil palm. PLOS ONE 10: e0122432.

Mayhew RJ, Tobias JA, Bunnefeld L, Dent DH. 2019. Connectivity with primary forest determines the value of regenerating tropical forests for bird conservation. Biotropica 51: $219-233$.

McGarigal K, Cushman S, Ene E. 2012. FRAGSTATS v4: Spatial pattern analysis program for categorical and continuous maps. University of Massachusetts, Amherst. http://www.umass.edu/landeco/research/fragstats/fragstats.html

Mesquita RCG, Delamônica P, Laurance WF. 1999. Effect of surrounding vegetation on edge-related tree mortality in Amazonian forest fragments. Biological Conservation 91: 129_ 134.

Millan CH, Develey PF, Verdade LM. 2015. Stand-level management practices increase occupancy by birds in exotic Eucalyptus plantations. Forest Ecology and Management 336: $174-182$. 
Moreira, JMM, Rodriguez LCE, Caixeta-Filho JV. 2013. An optimization model to integrate

459 forest plantations and connecting corridors. Forest Science 59:661-669.

Moura NG, Lees AC, Andretti CB, Davis BJW, Solar RRC, Aleixo A, Barlow J, Ferreira J,

Gardner TA. 2013. Avian biodiversity in multiple-use landscapes of the Brazilian Amazon.

462 Biological Conservation 167: 339-348.

Myers N, Mittermeier RA, Mittermeier CG, da Fonseca GAB, Kent J. 2000. Biodiversity hotspots for conservation priorities. Nature 403: 853-858.

Nájera A, Simonetti JA. 2010. Enhancing avifauna in commercial plantations. Conservation Biology 24: 319-324.

Oksanen J, Blanchet G, Friendly M, Kindt R, Legendre P, McGlinn D, Minchin PR, O'Hara RB, Simpson GL, Solymos P, et al. 2016. Vegan: community ecology package. https://cran.r-project.org/package=vegan.

Parker III TA, Stotz DF, Fitzpatrick JW. 1996. Ecological and distributional databases. In: Stotz DF, Fitzpatrick JW, Parker III TA, Moskovits DK (Eds.), Neotropical Birds: Ecology and Conservation. The University of Chicago Press, Chicago, pp. 111-410.

Pfeifer M, Lefebvre V, Peres CA, Banks-Leite C, Wearn OR, Marsh CJ, Butchart SHM, Arroyo-Rodríguez V, Barlow J, Cerezo A, et al. 2017. Creation of forest edges has a global impact on forest vertebrates. Nature 551: 187-191.

Prevedello JA, Vieira MV. 2010. Does the type of matrix matter? A quantitative review of the evidence. Biodiversity and Conservation 19: 1205-1223.

Prugh LR, Hodges KE, Sinclair ARE, Brashares JS. 2008. Effect of habitat area and isolation 479 on fragmented animal populations. Proceedings of the National Academy of Sciences of the 480 United States of America 105: 20770-20775. 
481 R Core Team, 2016. R: A language and environment for statistical computing. R Foundation 482 for Statistical Computing, Vienna, Austria. https://www.r-project.org/.

Renjifo LM. 2001. Effect of natural and anthropogenic landscape matrices on the abundance of subandean bird species. Ecological Applications 11: 14-31.

Ribeiro MC, Metzger JP, Martensen AC, Ponzoni FJ, Hirota MM. 2009. The Brazilian Atlantic Forest: How much is left, and how is the remaining forest distributed? Implications for conservation. Biological Conservation 142: 1141-1153.

Ricketts TH, Regetz J, Steffan-Dewenter I, Cunningham SA, Kremen C, Bogdanski A, Gemmill-Herren B, Greenleaf SS, Klein AM, Mayfield MM, et al. 2008. Landscape effects on crop pollination services: are there general patterns? Ecology Letters 11: 499-515.

Ruffell J, Clout MN, Didham RK. 2017. The matrix matters, but how should we manage it? Estimating the amount of high-quality matrix required to maintain biodiversity in fragmented landscapes. Ecography 40: 171-178.

Santos-Barrera G, Urbina-Cardona JN. 2011. The role of the matrix edge dynamics of amphibian conservation in tropical montane fragmented landscapes. Revista Mexicana de Biodiversidad 82: 679-687.

Schielzeth H, Nakagawa S. 2013. Nested by design: Model fitting and interpretation in a mixed model era. Methods in Ecology and Evolution 4: 14-24.

Solar RRC, Barlow J, Ferreira J, Berenguer E, Lees AC, Thomson JR, Louzada J, Maués M, Moura NG, Oliveira VHF, et al. 2015. How pervasive is biotic homogenization in human modified tropical forest landscapes? Ecology Letters 18: 1108-1118. Y, Crist TO, Dormann CF, et al. 2012. Landscape moderation of biodiversity patterns and processes - eight hypotheses. Biological Reviews 87: 661-685. 
505 Umetsu F, Pardini R. 2007. Small mammals in a mosaic of forest remnants and

506 anthropogenic habitats - evaluating matrix quality in an Atlantic forest landscape. Landscape

507 Ecology 22: 517-530.

508 Watling JI, Nowakowski AJ, Donnelly MA, Orrock JL. 2011. Meta-analysis reveals the

509 importance of matrix composition for animals in fragmented habitat. Global Ecology and

510 Biogeography 20: 209-217.

511

512

513

514

515

516

517

518

519

520

521

522

523

524

525

526

527

528

529

530 
$531 \quad$ Figure 1 - (a): Map of sample site locations. Forest cover (all forest types) is shown in gray

532 and represents areas with $>50 \%$ canopy closure in 2000 (Appendix S1: Hansen et al.

533 (2013)/UMD/Google/USGS/NASA - Licensed under a Creative Commons Attribution 4.0

534 International License - https://creativecommons.org/licenses/by/4.0/). (b) and (c): composite

535 forest cover map and sampling points within transects for a fragmented site (b) and a

536 continuous site (c), forest is shown in gray and non-forest in white. Point counts formed a

537 regular (where terrain, patch size and edge shape allowed) nine-point grid spaced by $75 \mathrm{~m}$.

538 Three points were situated in each position - interior, edge and matrix.

539 Figure 2-Richness and composition measures for bird communities found at each site

540 partitioned by transect type for continuous forest (CF), continuous plantation (CE),

541 continuous pasture (CP), fragment interiors (I), fragments edges (E) and the surrounding

542 matrix (M). Results are shown for control landscapes (top) and fragments (below) as well as

543 for all species, forest species and disturbance adapted species. Letter labels show transect

544 type groupings based on post-hoc significance tests. Fragments with pasture matrices are

545 represented in white and plantation matrices in light gray. Continuous forest is indicated in

546 dark gray.

547 Figure 3 - Partial residual values for community integrity and disturbance-tolerant species

548 richness (DSR) against patch size in ha ( $a$ and c) and percentage forest cover (b and d) for

549 interior transects. Plantation matrix fragments are shown in black, pasture in gray.

550 Figure 4 - Partial residual values for community integrity, species richness, disturbance-

551 tolerant species richness (DSR) and forest species richness (FSR) against patch size in ha

552 (b and d) and percentage forest cover ( $a, c$, e and f) for edge $(a-d)$ and matrix $(e-f)$

553 transects. Plantation matrix fragments are shown in black, pasture in gray. $\mathrm{d}$ shows only a

554 single line as matrix type was not found to be influential in this model. 
Figure 5-Community integrity against forest cover percentage (a) and species richness (b)

557 compared between the two matrix types - Eucalyptus plantation (Eu) and pasture (Pa). Gray 558 is used for pasture matrix fragments with black representing plantation.
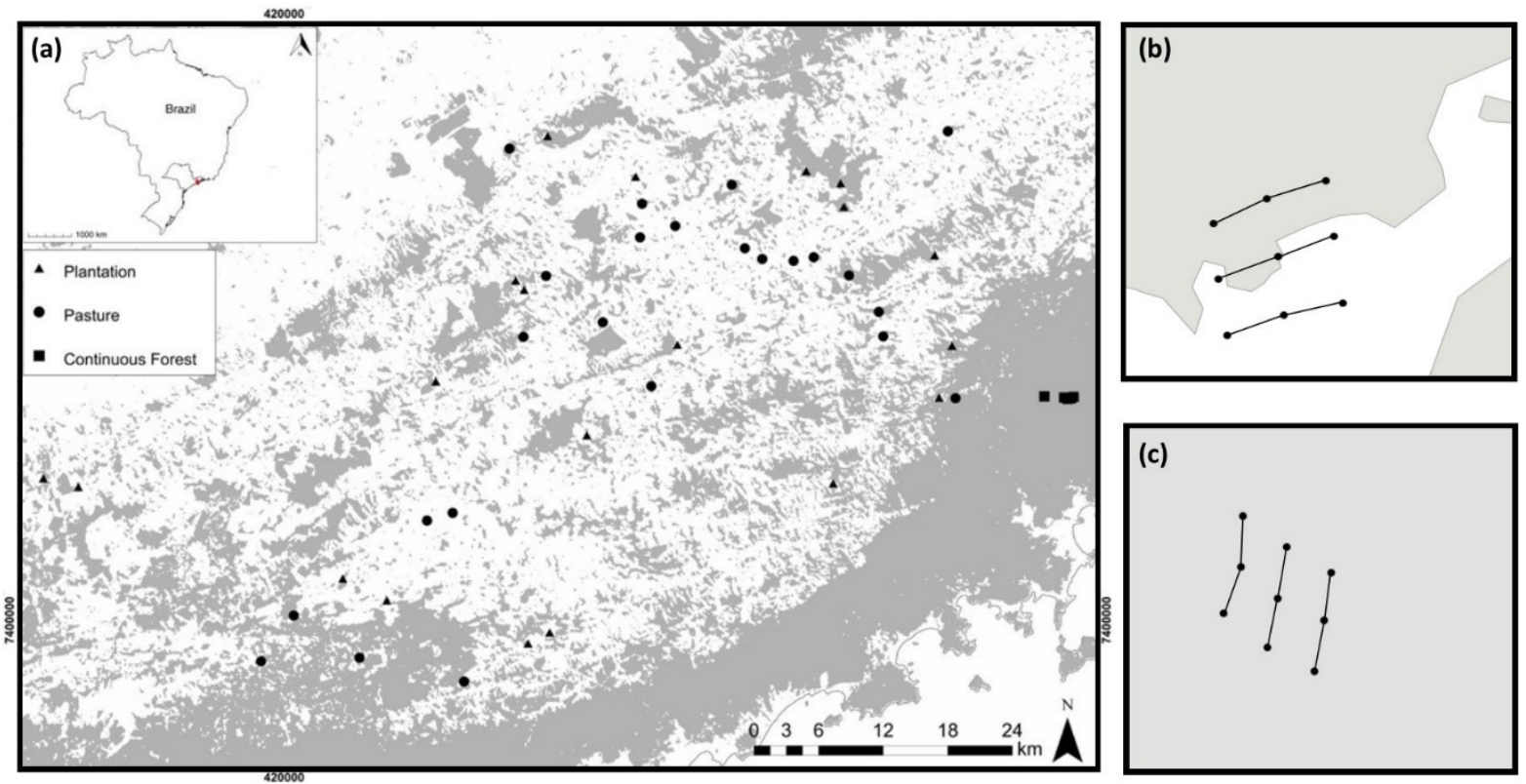

562

Figure 1-(A): Map of sample site locations. Forest cover (all forest types) is shown in gray and represents areas with > 50\% canopy closure in 2000 (Appendix S1: Hansen et al. (2013)/UMD/Google/USGS/NASA - Licensed under a Creative Commons Attribution 4.0 International License - https://creativecommons.org/licenses/by/4.0/). (B) and (C): composite forest cover map and sampling points within transects for a fragmented site (B) and a continuous site (C), forest is shown in gray and non-forest in white. Point counts formed a regular (where terrain, patch size and edge shape allowed) nine-point grid spaced by $75 \mathrm{~m}$. Three points were situated in each position - interior, edge and matrix. 
All

(a)

574

575

576

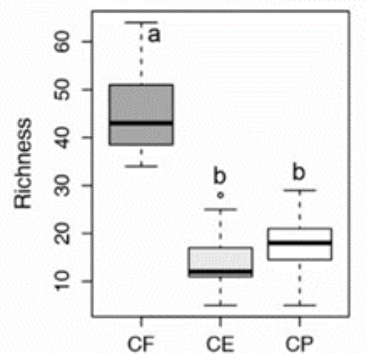

577

578

579

580

581

582

583

584

585

586

587

588 (c)
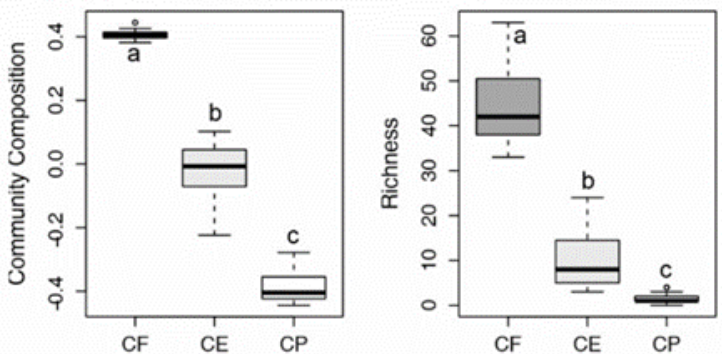

(g)

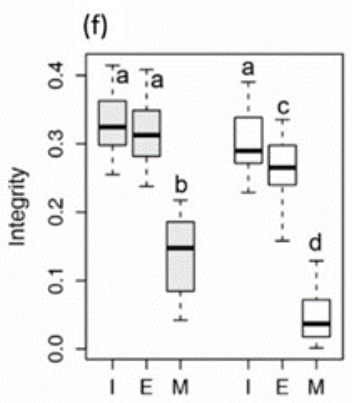

Disturbance Adapted

(d)
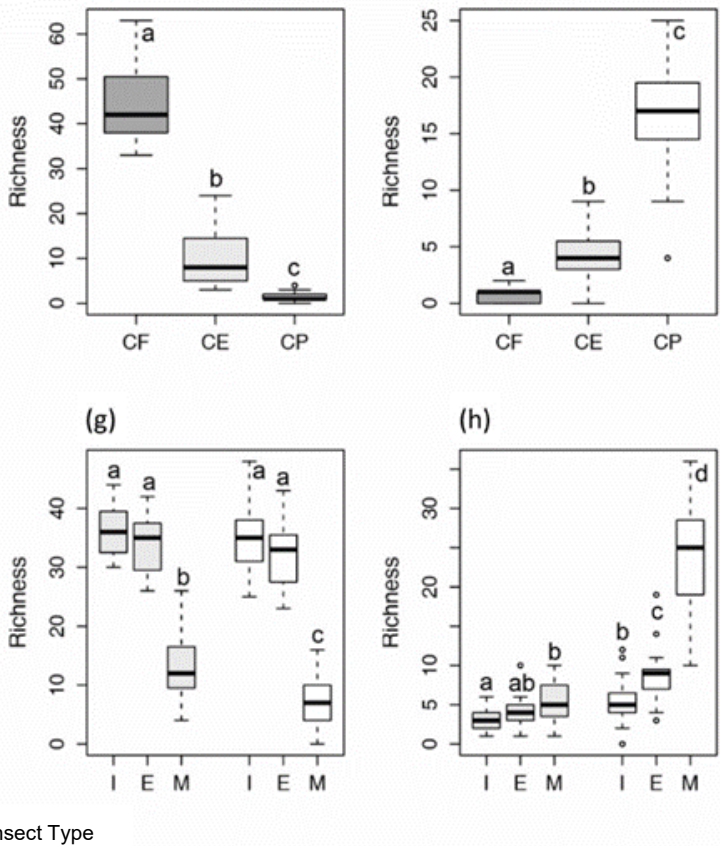

(h)

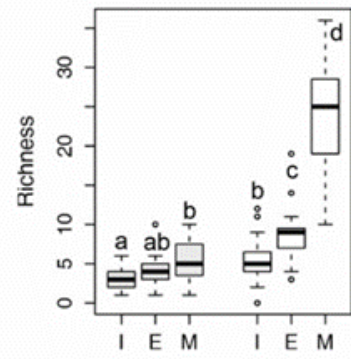

Figure 2 - Richness and composition measures for bird communities found at each site partitioned by transect type for control forest (CF), control plantation (CE), control pasture $(\mathrm{CP})$, fragment interiors $(\mathrm{I})$, fragments edges $(\mathrm{E})$ and the surrounding matrix $(\mathrm{M})$. Results are shown for control landscapes (top) and fragments (below) as well as for all species, forest species and disturbance adapted species. Letter labels show transect type groupings based on post-hoc significance tests. Fragments with pasture matrices are represented in white and plantation matrices in light gray. Control forest is indicated in dark gray. 


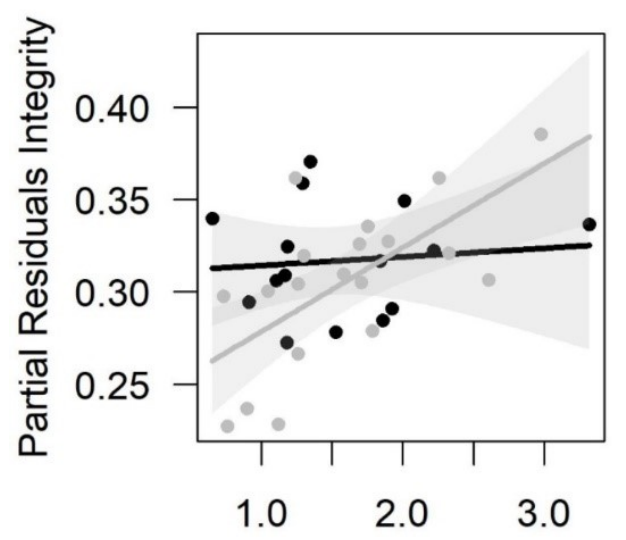

Patch Size $(\log 10)$

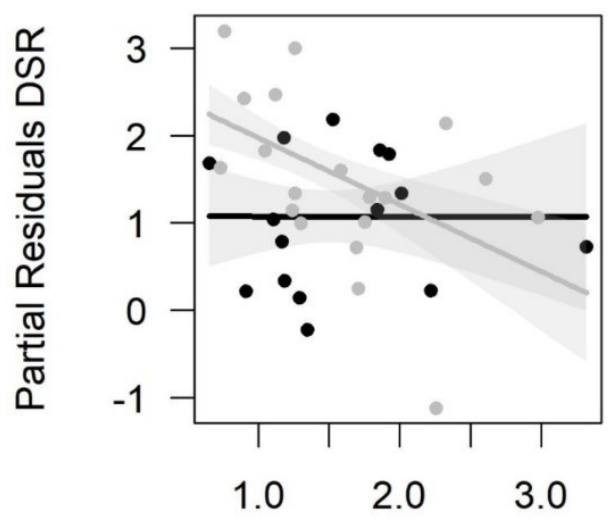

590
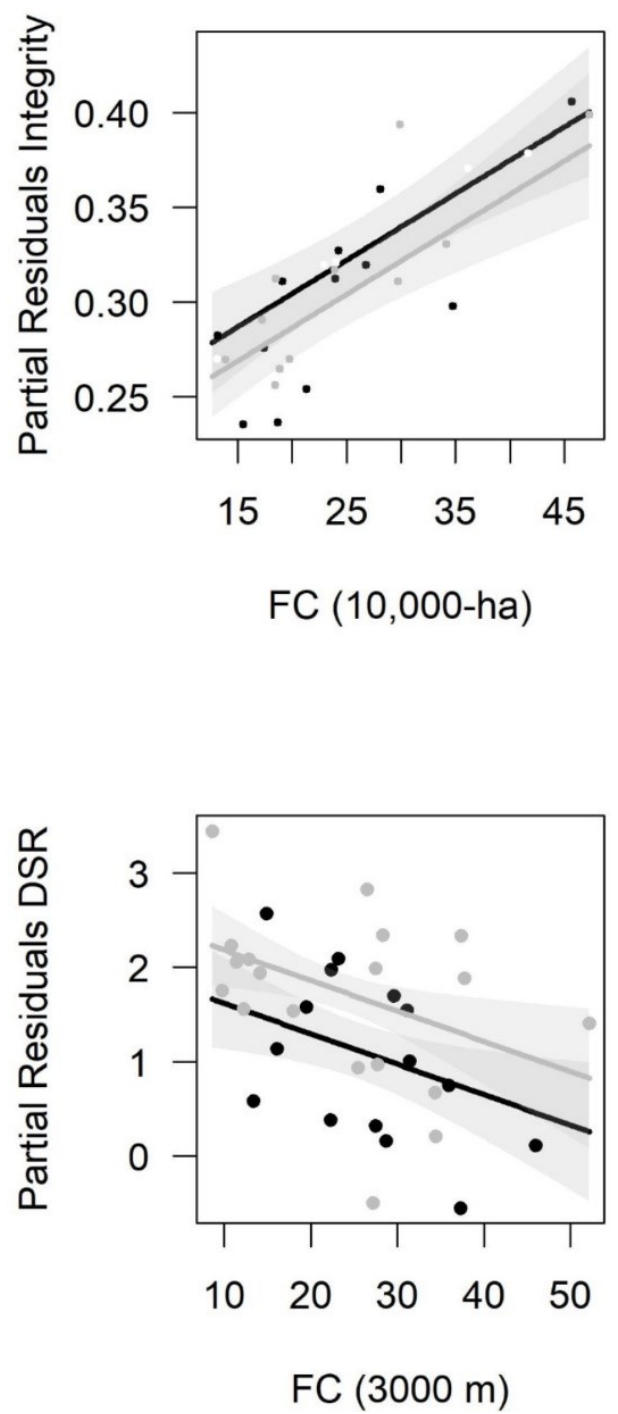

591 Figure 3 - Partial residual values for community integrity and disturbance-tolerant species

592 richness (DSR) against patch size in ha ( $a$ and $c)$ and percentage forest cover (b and d) for

593 interior transects. Plantation matrix fragments are shown in black, pasture in gray. 
Fragment Edge

(a)

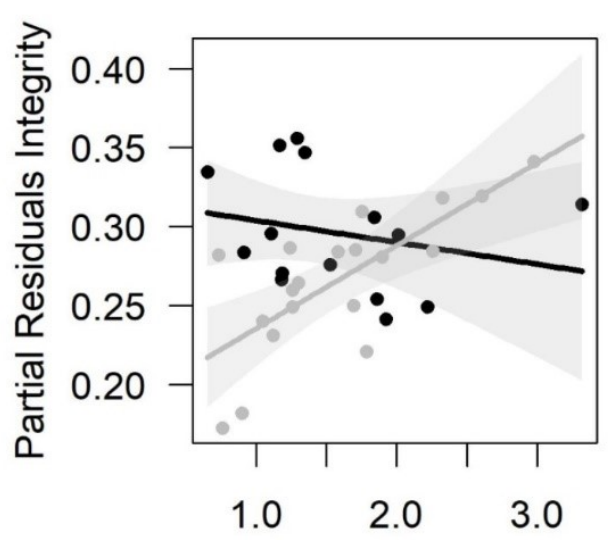

Patch Size $(\log 10)$

(c)

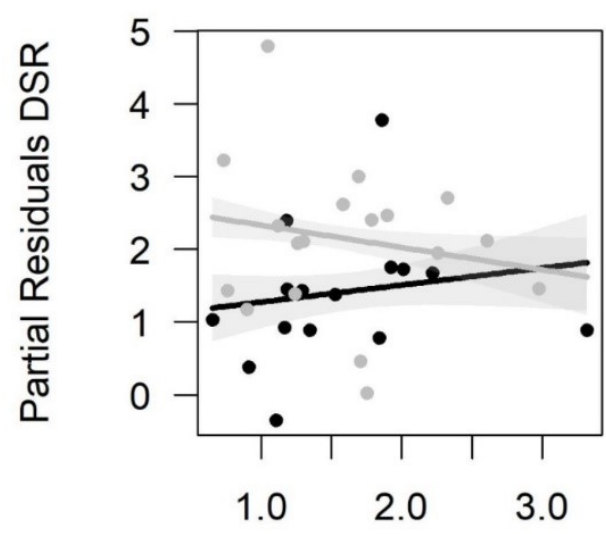

Patch Size $(\log 10)$

\section{Matrix}

(e)

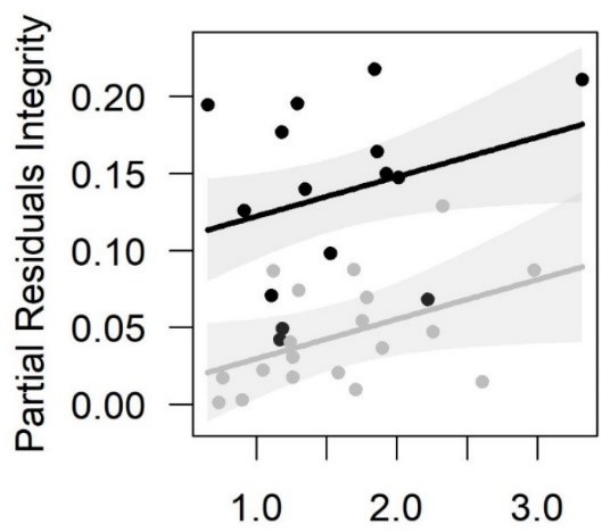

(b)

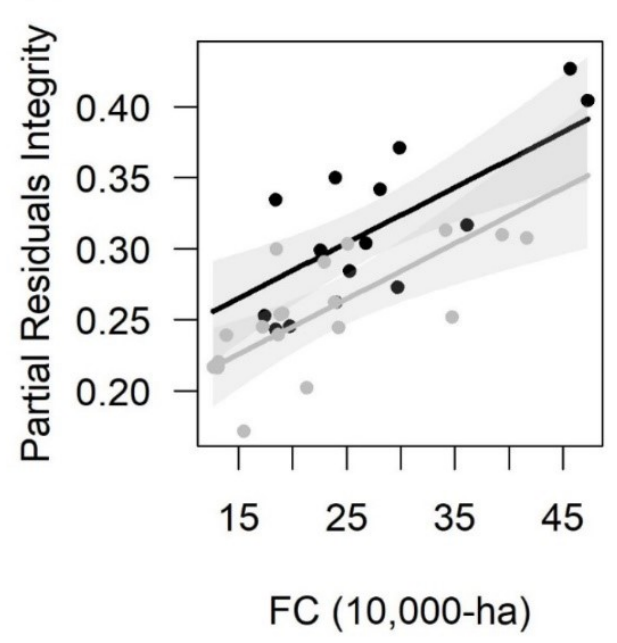

(d)

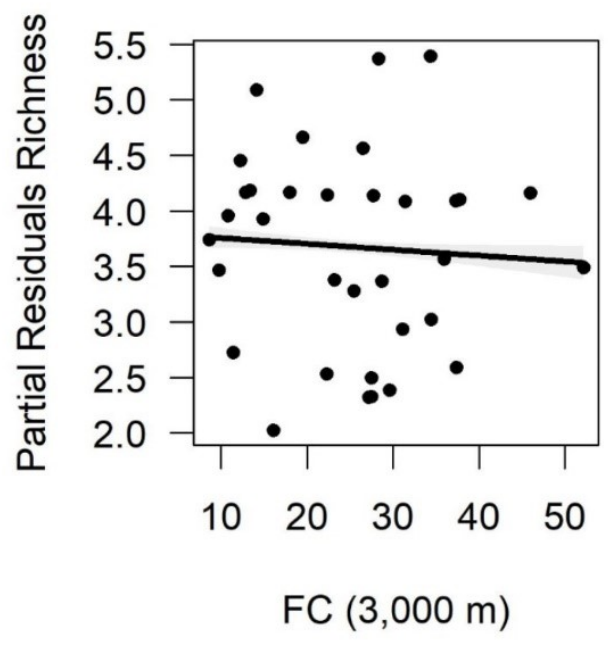

(f)

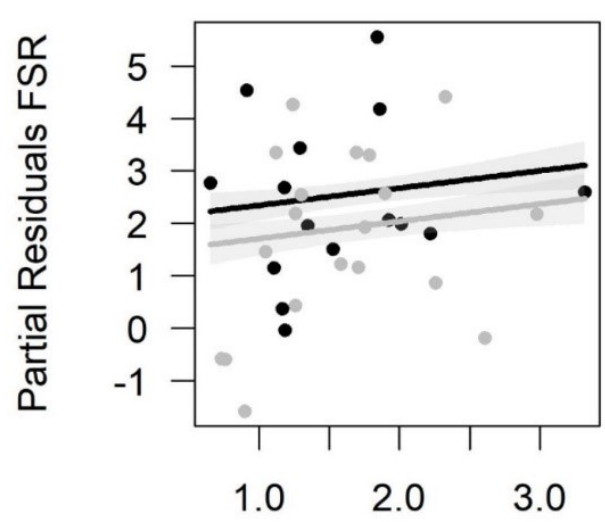

Patch Size $(\log 10)$ 
595 Figure 4 -Partial residual values for community integrity, species richness, disturbance

596 tolerant species richness (DSR) and forest species richness (FSR) against patch size in ha

597 (b and d) and percentage forest cover ( $a, c$, e and f) for edge (a - d) and matrix (e - f)

598 transects. Plantation matrix fragments are shown in black, pasture in gray. $d$ shows only a

599 single line as matrix type was not found to be influential in this model.

600

(a)

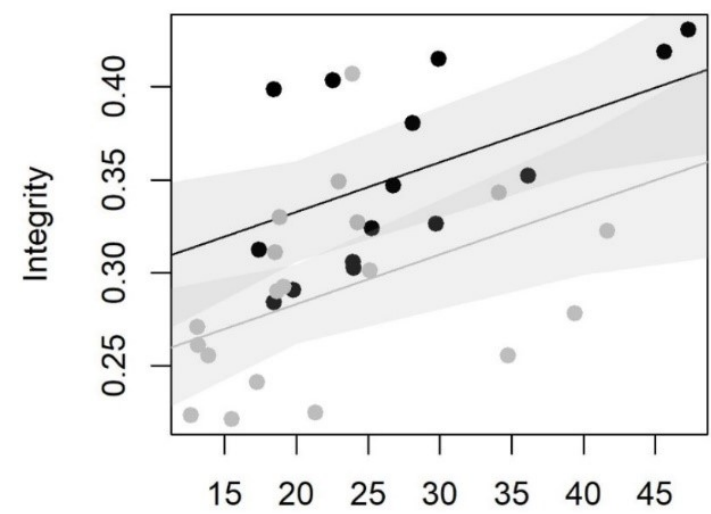

FC $(10,000-h a)$ (b)

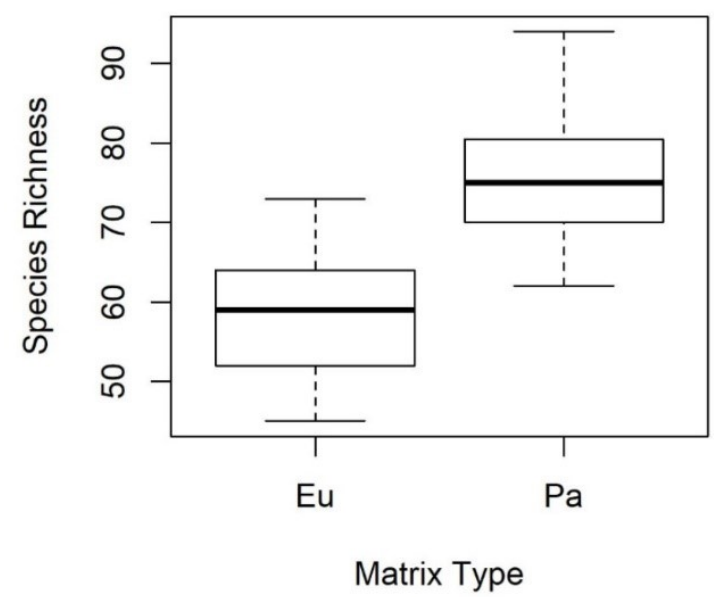

601

602 Figure 5-Community integrity against forest cover percentage (a) and species richness (b)

603 compared between the two matrix types - Eucalyptus plantation (Eu) and pasture (Pa). Gray

604 is used for pasture matrix fragments with black representing plantation. 